\title{
Design and implementation of irrigation prototype system based GSM
}

\author{
M. F. Obead*1, I A. Taha ${ }^{2}$, A. H. Salman ${ }^{3}$ \\ ${ }^{1,2,3}$ Department of computer technical engineering, Al-Esra'a University College, Baghdadm, Iraq \\ muhammad.fahim@esraa.edu.iq
}

\begin{abstract}
Smart farming is one of the keys for future agriculture because it is a management to use modern technology for increasing the quality and quantity of the agriculture. And because of the planet quality depend on the amount of water and the characteristics of soil, it is necessary to study the soil using the soil moisture sensor to investigate whether the soil is dry or wet, also to consider the challenges that could be faced in agricultural environment by maintain the soil and the planets irrigated without extra usage of water. In this paper, a prototype irrigation system uses Arduino Uno microcontroller which is programmed in $\mathrm{C}++$ language to sense the degree of moisture by using soil moisture sensor. According to moisture sensor readings, when the moisture sensor above 1000, Arduino triggers to supply the water by using $5 \mathrm{~V}$ mini water pump and stop when the soil moisture sensor reading reaches below 400. GSM technology enables the user to be notified in any changes happening in agricultural area by sending SMS (Short Message Service). Whenever the soil become wet or dry and the mini water pump switched on or off, a message delivered to user's cellular phone indicating the condition of the soil and the action of water pump. In that capacity, this prototype will reduce the time for the user by monitoring remotely without going to his land, and also to reduce the usage of water by allow the water pump to flow the water for limited time until the moisture degree raise again.
\end{abstract}

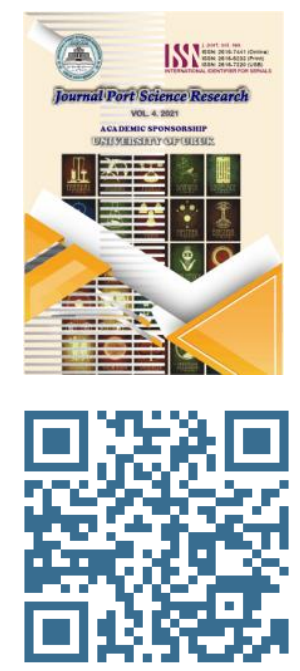

Crossref

$10.36371 /$ port.2021.2.5

Keywords: Smart farming, Agriculture, Arduino, moisture sensor, GSM.

\section{INTRODUCTION}

The agriculture represents the major fortune and the backbone for some countries due to their rule of increasing the income of economic activity. The continuous growing of the population of a nation requires more innovation in food production technology. As there are many factors directly effecting on the agricultural progresses, these factors must be study carefully to get the best results [1] Agricultural lands normally are far away from farmers houses, so it would be irrational to go from their place to irrigate, as it could be fuel consumption also manual watering has no limits, which could be wastage of water. Add on there are some agricultural pesticides that are included in the transplant process, which directly affect the health of the farmer. Irrigation is the efficient system that could simulate ample effects on agriculture like dryness that may classify as the main problem that can directly effect on the seeding plant and it is a result of global warming. Increasing in temperature causes the soil to be too dry and not suitable for agriculture, and it will be malnutrition since the activity of microbial supplies the nutrients to the planet [2]. Some of people irrigate their farms, gardens and small home plants every day regularly, but some of them find it challenge to maintain their plant watered due to busy schedule during the day hours. For the reasons above, the objective of studying an automatic irrigation is to sense the humidity of the soil so that can irrigate the exact amount of water to the plants. In this project, the system will be used to remotely monitor the irrigation system for watering using the combination of Microcontroller Arduino, GSM and moisture sensor. The moisture sensor will sense the soil to check its condition through a programmable reading referring to sensor specification, then the microcontroller will receive the reading of the sensor and translate it based on the value condition. The GSM technology provides text data services and will send a short message to the user's cell phone and this is the main benefit of using GSM.[3] .

\section{LITERATURE REVIEW}

[4]Parameswaran, G. \& Sivaprasath, K. proposed a smart drip irrigation system by using IOT. Environmental parameter such as $\mathrm{PH}$, humidity and temperature has been sensed. Server/local host used to update the status of irrigation by using personal computer.

[5]Archana, P. \& Priya, R. Proposed Sensors are set in the root zone of the planet and implemented to detect any change in soil moisture, The sensors which has been used are not activated until the water is present. Any change in the degree of moisture in the soil, the microcontroller switches to activate the motor ON/OFF based on the sensor readings values.

[6]Apoorva Joshi \& Layak Ali The have developed a very basic and low-cost system built around Atmel's 
microcontroller "AT89S52" The system is put in the field for working and tested well for the Operation.

\section{METHODOLOGY}

The project constructed as a prototype that will detect the moisture level in the soil by using moisture sensor. The Arduino Uno is the heart of the electronic circuit, the soil moisture, GSM and water pump all connected to the Arduino, the watering operation is depend on moisture level to trigger the water pump as shown in the figure below:

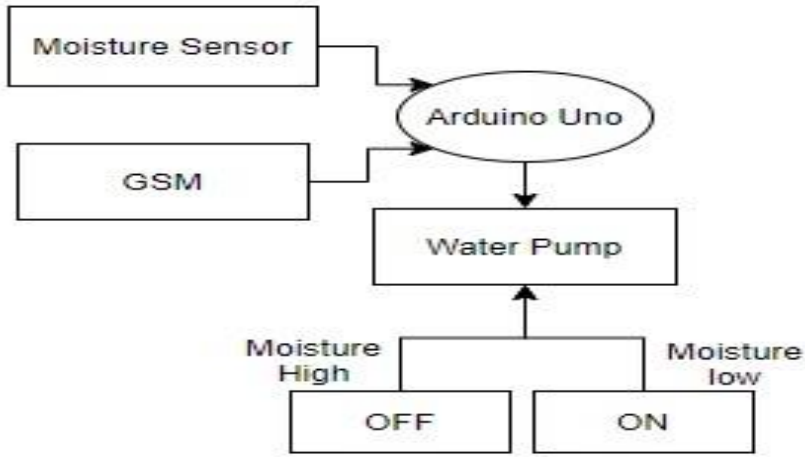

Figure 1. Watering system block diagram.

\section{SYSTEM COMPONENTS}

A. ARDUINO UNO. Arduino Uno is an open source electronic device can be programmed to perform several tasks. It can read input devices and send information to the output devices. Arduino Uno constructed from to basic parts, physical part which is programmable circuit (microcontroller) and software part is IDE (Integrated development environment) that operate the program code on computer [7].

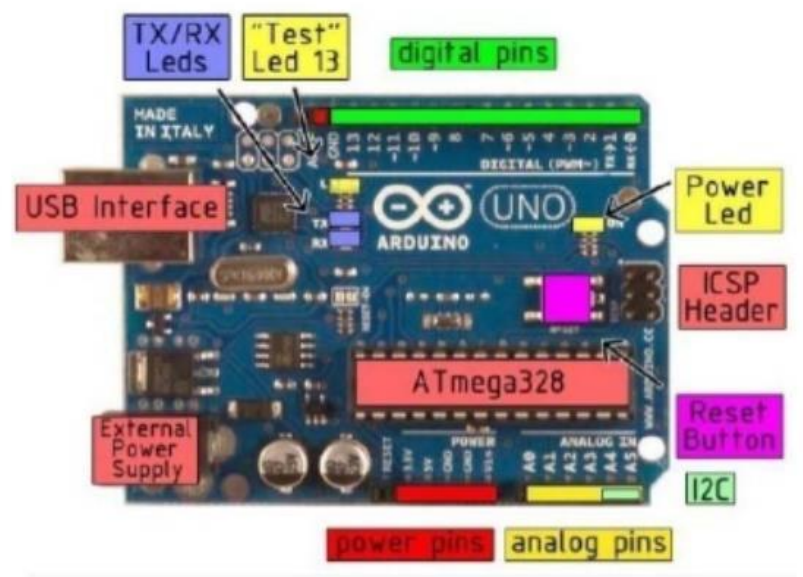

Figure. 2 Arduino uno board. (7).

\section{B. SOIL MOISTURE SENSOR (YL-69)}

Moisture sensor is an electronic device used to monitor the moisture in the soil to prevent it to become too dry or too wet. Soil moisture sensor (YL-69) uses resistance to determine the isolation permittivity of the medium. Isolation permittivity is water content function. The sensor initiates current throughout the whole two probes to determine the moisture in the soil. Soil moisture is shown in figure below [8]:

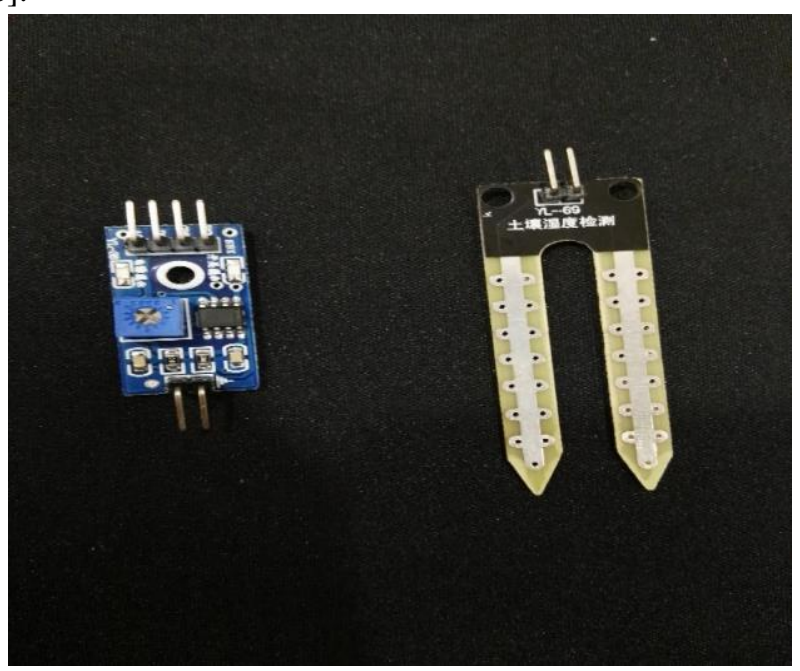

Figure.3. Moisture sensor Yl-69.

YL-69 sensor has the flowing Readings for Loam soil TABLE 1. Sensor readings referring to loam soil condition.

\begin{tabular}{lcc}
\hline Condition & Minimum reading & Maximum reading \\
\hline Sensor in wet soil & $350 \sim$ & 600 \\
$\begin{array}{l}\text { Sensor in semi } \\
\text { humid soil }\end{array}$ & $600 \sim$ & 950 \\
Sensor in dry soil & 950 and Above & $/$ \\
\hline
\end{tabular}

The above tables shows each reading of the moisture sensor in different conditions (wet, semi humid and dry) and indicated the minimum and maximum readings for each. Those readings differ for different soils. In this condition, sandy soil has been used.

\section{GSM SIM 900A}

GSM is a device use to make a connection with the cellular phone/computer. GSM module construct from a modem and power supply and communication circuit interfaces such as RS 232 and USB. A SIM card is inserts in SIM place like mobile phone to make a connection. It can perform sending and receiving short messages service, also can explore the content of SIM card and establishing or rejecting the voice call all that can operate at low power consumption [9].

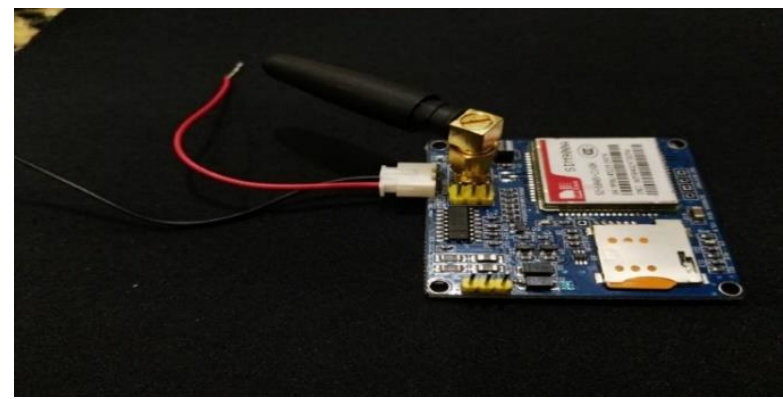

Figure.4 GSM module. 


\section{DC WATER PUMP}

The water pump has two channels, one channel is connected to the water source and another is used to take the water to the area to be irrigated. The water pump is controlled by motor driver [10].

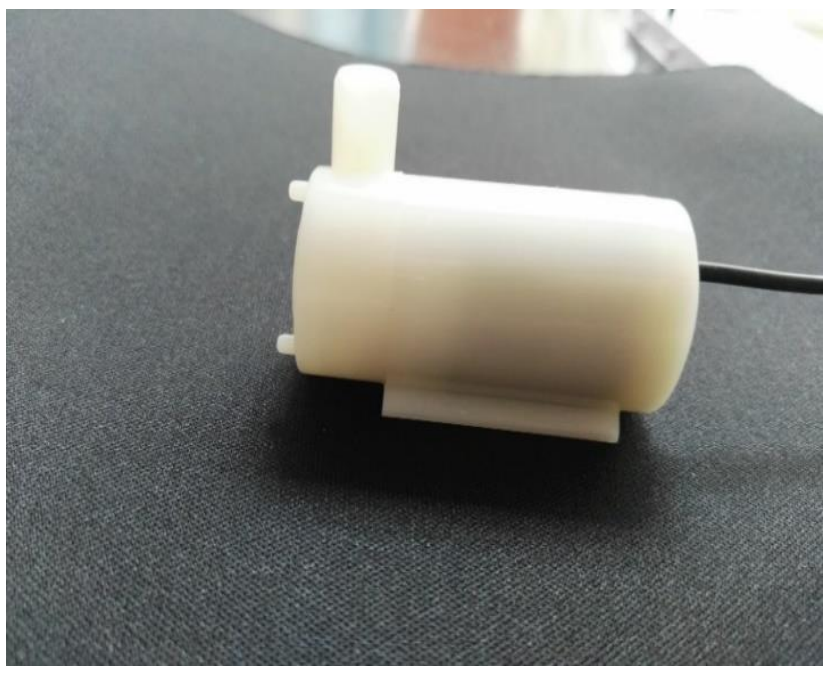

Figure. 5 Dc Water pump

\section{WATERING IRRIGATION SYSTEM}

The first operation starts from the moisture sensor as it refers to the amount of water in the soil. The moisture sensor principle will be based on readings previously programmed by the used and specified for each case whether the soil is wet or dry or normal, the readings can be tabled as following:

TABLE 2. Sensor readings.

\begin{tabular}{lcc} 
Sensor reading & Soil Condition & Action \\
\hline $\mathbf{3 5 0 - 6 0 0}$ & Wet & No water flow \\
$\mathbf{6 0 0 - 9 5 0}$ & Semi wet & No water flow \\
$\mathbf{9 5 0}$ Above & Dry & Water flow \\
\hline
\end{tabular}

Referring to these values, when the sensor readings varies between 350 to 600 this means that the soil is wet and no need for irrigation, when the sensor reading vary between 600 to 950 this means that the soil is in normal condition and there is also no water flow, when the sensor readings exceeded 950 this means that the soil is dry and the water pump is switched ON, These indications will be transmitted as a signal to Arduino Uno microcontroller that will establish a serial connection with GSM to send an SMS to the user.

RESULTS

The system hardware is as shown below:

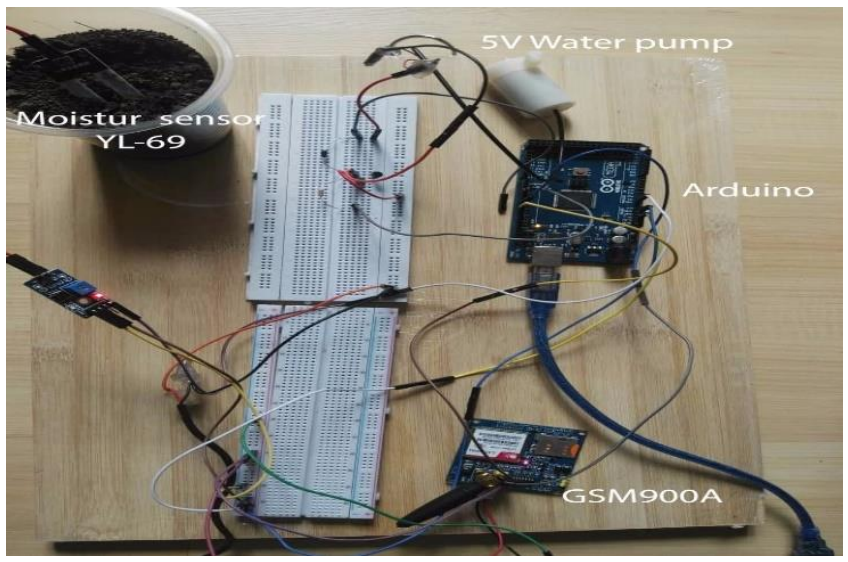

Figure 6. Complete hardware circuit of the system.

\section{SYSTEM PERFORMANCE}

At the start of the operation, Arduino IDE used to monitor the behavior of the sensor serially and the sensor value set to be an analog value change continuously. When the sensor is inside dry soil, the readings reach above 1000, Arduino triggers to that value and the serial monitor indicates "soil is dry ... motor is ON ... soil is $0 \%$ wet", a message is sent to the user "soil is dry ... motor is ON" through the GSM.

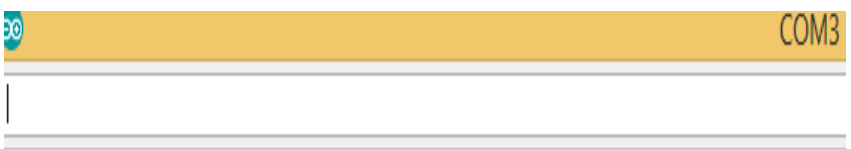

Reading From the Sensor ...

noisture: 1023

30 il is dry , motor is ON....soil is 0 of wet

nessage sent.

noisture: 1023

noisture: 1023

noisture: 1023

noisture: 1023

noisture: 1023

Figure 7. Serial readings of the sensor indicating the dryness.

Meanwhile, a message will be delivered to user's cellular phone as in the following figure:

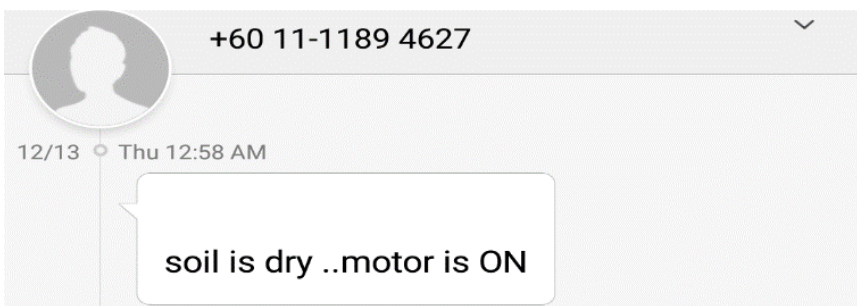

Figure 2. Monitoring through user's mobile via SMS. 
While the water pump irrigating the soil, the sensor keeps checking the soil moisture level and when it reaches threshold value of approximately 400, "soil is wet... motor is OFF" and irrigation operation stop automatically as shown below:

\begin{tabular}{l}
\hline \\
\hline Reading From the Sensor ... \\
moisture: 1023 \\
soil is dry ...motor is oll....soil is 0 s wet \\
message sent. \\
moisture: 1023 \\
mo1sture: 1023 \\
moisture: 1023 \\
moisture: 1023 \\
moisture: 500 \\
soil is wet ...motor is OrF ...soil is 83.338 wetmoisture: 390 \\
moisture: 464 \\
moisture: 485 \\
moisture: 478
\end{tabular}

Figure 9. Serial readings of the sensor indicating the wetness.

Also, a message will be delivered to the user cellular phone indicating the soil has been irrigated and the motor switched OFF as i below:

\section{soil is wet ..motor is OFF}

Figure 10. Monitoring through user's mobile via SMS.

\section{A. SENSOR READINGS}

Working principle of moisture sensor probes based on measuring the dielectric permittivity of the surrounding medium by creating voltage proportional to it, resulting the two probes exposed to conduct and act as variable resistor varies according to the content of soil. More water means less resistance which means less voltage when detects moisture.

The voltage measured for moisture sensor at wet, dry and normal condition is as tabulated below:

TABLE 3 Sensor output in volt at each moisture degree

\begin{tabular}{lc} 
Soil condition & Sensor output \\
\hline Dry & $4.1 \mathrm{~V}$ \\
Normal & $3.3 \mathrm{~V}$ \\
& \\
Wet & $2.37 \mathrm{~V}$
\end{tabular}

From the data obtained in the table above, it can be represented graphically below:

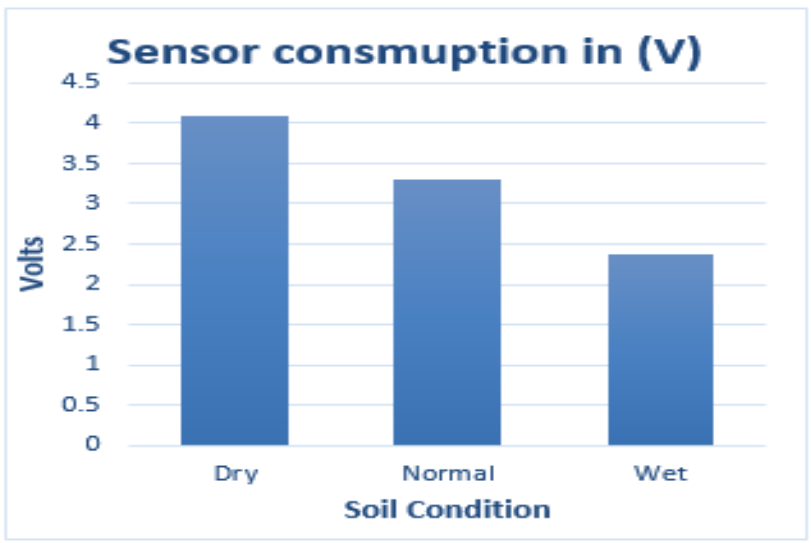

Figure 11. Sensor output in volt at each moisture degree graphically.

The X-Axis represent the volts consumed by the sensor and

Y-Axis represent the soil condition. The obtained data shows the highest peak in dry condition because the current across sensor probes is very low due to high resistance

\section{B. AFFECTION OF SOIL CONTENT ON SENSOR READINGS}

The sensor probes affect by how much soil covers the probes and what is the type of the soil. Loam soil has been used in this prototype which is a mixture of sand and small amount of clay. The test for loam has been done and sensor readings has been recorded gradually by adding small drops of water (readings may vary depending on soil type and sensor calibration). The tested results shown in the table below

TABLE 4. Soil water content vs. sensor readings

\begin{tabular}{lc} 
Soil water content $(\mathbf{c m} 3)$ & Sensor output \\
\hline 0 & 1023 \\
25 & 905 \\
50 & 839 \\
75 & 644 \\
100 & 324 \\
\hline
\end{tabular}

\section{SENSOR ACTIVITY AGAINST TIME}

Sensitivity of YL-69 is analog unit per $1 \mathrm{sec}$, if 10 second taken as sample, the following graph will show how the 
sensor react to witness when uncertain amount of water added to a small amount of dry soil gradually:

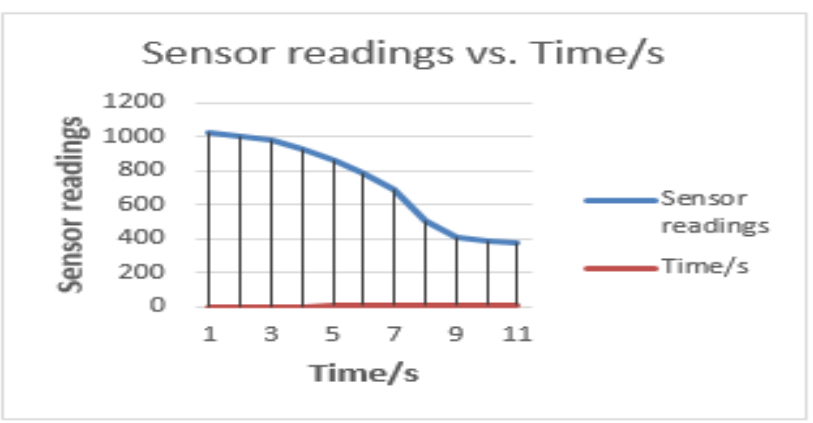

Figure 12. Sensor behavior against time

As it can be seen from graph above, the sensor is at dry soil on its peak analog value (1023) and start decaying when water added to the probes place until it reaches maximum wetness (400-350).

\section{CONCLUSION}

"GSM Activated Watering System Prototype "has been achieve maximum protection for crops by irrigating exact amount of water for helping the user to get optimum agricultural. And that is also will help to use the water in proper way, besides, automatic irrigation economizes the user time and energy by monitoring his land remotely. Because the soil moisture varies from crop to another, so the moisture sensor is responsible of sense that moisture level in the soil. The system tested successfully, and it has been developed by hardware components. Soil moisture function is to indicate the moisture degree in the soil. If the moisture degree below the desired level, the moisture sensor sends a signal to Arduino Uno microcontroller to trigger the water pump ON to start soil irrigating operation and the GSM module send an SMS to the user notifying about soil condition and the water pump state, when the desired moisture reached, the system stops automatically, and water pump is turned OFF. Thus, all the system function working properly.

To improve optimum agricultural and to take control of everything around plantation circumstances, temperature sensor can be added to the system and that is particularly for covered agriculture.

To reduce the cost in general, Wifi can be used instead of GSM to monitor the green land.

\section{Acknowledgment}

I am grateful to all of those with whom I have the pleasure to work during this and other related papers. As well as for everyone who taught me a letter during my studies until I reached this stage of knowledge

\section{REFERENCES}

[1] Ishak, Ishak, N. S., Awang, A. H., Bahri, N. N. S., \& Zaimi, A. M. M. (2016). GSM activated watering system prototype. In RFM 2015 - 2015 IEEE International RF and Microwave Conference (pp. 252-256). Institute of Electrical and Electronics Engineers Inc. https://doi.org/10.1109/RFM.2015.7587756

[2] Prasojo, I., Maseleno, A., Tanane, O., \& Shahu, N. (2020). Design of automatic watering system based on arduino. Journal of Robotics and Control (JRC), 1(2), 55-58. https://doi.org/10.18196/jrc.1213

[3] Karmokar, C., Hasan, J., Khan, S. A., \& Ibne Alam, M. I. (2018). Arduino UNO based Smart Irrigation System using GSM Module, Soil Moisture Sensor, Sun Tracking System and Inverter. In 2018 International Conference on Innovations in Science, Engineering and Technology, ICISET 2018 (pp. 98-102). Institute of Electrical and Electronics Engineers Inc. https://doi.org/10.1109/ICISET.2018.8745597

[4] Parameswaran, G., \& Sivaprasath, K. (2016). Arduino Based Smart Drip Irrigation System Using Internet of Things. International Journal of Engineering Science, 6(5). DOI 10.4010/2016.1348

[5] Archana, P., \& Priya, R. (2016). Design and Implementation of Automatic Plant Watering System. International Journal of Advanced Engineering and Global Technology, 4(01), 1567-1570. Retrieved from www.ijaegt.com

[6] Joshi, A., \& Ali, L. (2017). A detailed survey on auto irrigation system. In 2017 Conference on Emerging Devices and Smart Systems, ICEDSS 2017 (pp. 90-95). Institute of Electrical and Electronics Engineers Inc. https://doi.org/10.1109/ICEDSS.2017.8073665

[7] Saha, H. N., Banerjee, T., Saha, S. K., Das, A., Dutta, A., Roy, A., ... Chakravorty, N. (2019). Smart Irrigation System Using Arduino and GSM Module. In 2018 IEEE 9th Annual Information Technology, Electronics and Mobile Communication Conference, IEMCON 2018 (pp. 532-538). Institute of Electrical and Electronics Engineers Inc. https://doi.org/10.1109/IEMCON.2018.8614839 
[8] Ramachandran, V., Ramalakshmi, R., \& Srinivasan, S. (2018). An Automated Irrigation System for Smart Agriculture Using the Internet of Things. In 2018 15th International Conference on Control, Automation, Robotics and Vision, ICARCV 2018 (pp. 210-215). Institute of Electrical and Electronics Engineers Inc. https://doi.org/10.1109/ICARCV.2018.8581221

[9] Khulape, Miss. S. A., Malage, Miss. S. R., \& Chavan, Mr. S. V. (2018). Home Automation Android Based GSM System. International Journal of Trend in Scientific Research and Development, Volume-2(Issue-6), 774-777. https://doi.org/10.31142/ijtsrd18740

[10] Kumar, R., \& Singh, B. (2017). Single Stage Solar PV Fed Brushless DC Motor Driven Water Pump. IEEE Journal of Emerging and Selected Topics in Power Electronics, 5(3), 1377-1385. https://doi.org/10.1109/JESTPE.2017.2699918 